\title{
Interactive comment on "Large-scale application of the flood damage model Railway Infrastructure Loss (RAIL)" by Patric Kellermann et al.
}

\section{Anonymous Referee \#1}

Received and published: 9 September 2016

The paper describes the practical large-scale application of the empirical based flood damage model RAIL for the Railway infrastructure loss. These analyses are an interesting and relevant topic in the field of flood damage modelling on a special infrastructure sector.

The RAIL model is a relative simple damage model, but it follows an engineering based way and gives an estimation of a damage class for the description of the structural damage in dependence of the inundation height. The damage classes are connected with standardized repair costs for $100 \mathrm{~m}$ track length, which were derived in a former study.

In the paper the RAIL model was applied to the railway network of the ÖBB in the Mur River catchment. The expected annual losses were calculated on the basis of flood

Printer-friendly version

Discussion paper 
scenarios for three return periods.

The linkages between the individual steps of the described procedure are logical and comprehensible.

The authors are also aware of the limitations of the described procedure. It is clear that some simplifications (like equal construction heights for the substructure) must be taken for such a large investigation area also with respect to the availability of some necessary data. Finally the RAIL model itself is a simplification, because it reduces the problem (in comparison to the continuous relative damage functions of other models) to 3 values of absolute losses. Some of the uncertainties were considered in a limited range regarding the heights of the substructures of the track and the cost calibration factors for damage class 2 .

From the perspective of the referee are some comments necessary.

The first one refers the relatively low number of damage classes (in comparison to some damage models for other sectors). The increase of the values of these standard repair costs (which were derived in a former study) between the three damage classes is relative strong. So a slight increase of the water level can cause a relative strong (certainly unrealistic) jump in the expected losses for the track section if the threshold to the next higher class of damage is exceeded. This could be one reason for the large differences for the expected annual losses in the different operational sections. As appropriate, this could be discussed more in detail. For a further improvement of the damage model an increase of the number of damage classes could be checked or also the definition of a flexible range of standard repair costs (in the sense of a damage function) for the individual damage classes .

A second comment is related with calculation of the expected annual losses. The given standard repair costs refers in general to a price structure for a specified year. The calculation of an annual loss should consider the expected future increase of the repair cost. It is directly not visible in the paper, whether this has been taken into account. $A$

Printer-friendly version

Discussion paper 
short comment to this should be sufficient.

I look forward to the further progress of the model development and its application.

NHESSD

\section{Best regards}

Interactive comment on Nat. Hazards Earth Syst. Sci. Discuss., doi:10.5194/nhess-2016-259,

Interactive

comment 2016. 